\title{
Model to identify potentially preventable cerebral palsy of intrapartum origin
}

\author{
Geraldine Gaffney, Valerie Flavell, Ann Johnson, Marian V Squier, Susan Sellers
}

\begin{abstract}
A six stage model was applied to a geographically defined population of 210 singleton children born at term who had a diagnosis of cerebral palsy at 5 years of age. Thirty five children were identified as those most likely to have cerebral palsy of intrapartum origin; in 26 of these there was evidence of suboptimal care.

It is suggested that this simple model should be tested on populations of children with cerebral palsy and the underlying principles used when considering the likely cause of cerebral palsy in individual children.
\end{abstract}

(Arch Dis Child 1995; 73: F106-F108)

Keywords: cerebral palsy, intrapartum care, neonatal encephalopathy, fetal monitoring.

There are some children with cerebral palsy in whom a different pattern of care during labour and delivery would have changed the outcome. ${ }^{1-4}$ It is important to identify these children for two reasons. First, it may be possible to implement changes in management which would prevent further similar cases. Second, some parents of disabled children resort to civil court action, seeking damages for alleged negligence around the time of birth. Correct identification of the children who seem to suffer the effects of suboptimal obstetric care is a part of this litigation process.

Based on a review of existing epidemiological evidence of the current understanding of the origin of cerebral palsy, we developed a model which can be used to identify those children with cerebral palsy who are most likely to have had a preventable intrapartum event. ${ }^{5-24}$ A sequence of six questions is asked. The response 'No' excludes the child from further questions. We believe that these children remaining at the end of the sequence are most likely to have had an obstetrically preventable cause of cerebral palsy. The model was tested on a geographically defined population of children with cerebral palsy.

ohn Radcliffe Maternity Hospital, Oxford

S Sellers

Department of Neuropathology, Radcliffe Infirmary, Oxford

M V Squier

Correspondence to: Dr Ann Johnson.

Accepted 28 April 1995
1987. Details of the register are discussed elsewhere. $^{25}$

\section{Method}

The model consisted of the six questic (figure). This applied to $210 \mathrm{chil}$ on a regional cerebral palsy register who were at least 5 years old and who were
Results

The number of children excluded at each step in the model is shown in the figure.

\section{QUESTIONS}

(1) Postnatal cause Twenty seven children were identified as having a postnatal cause for cerebral palsy. The causes were meningitis in 12 , trauma in six, cerebrovascular accidents in three, postoperative anoxia in three and miscellaneous other events such as near-drowning in three.

(2) Prenatal cause Forty two children had an identifiable prenatal origin to their cerebral palsy. These included cerebral malformations $(n=10)$, cerebral vascular malformations $(n=7)$, metabolic and chromosomal causes $(n=7)$. Six had recognised syndromes, three had an intrauterine infection, and one child had a congenital ependymal tumour.

(3) Neonatal neurological dysfunction was present in 54 of the remaining 141 children. We thought it likely that among the 87 children excluded at this stage, some may have had an unrecognised prenatal origin for their cerebral palsy, but there was insufficient information available to support this.

(4) Depression at birth Forty six of the 54 babies with abnormal neonatal neurological signs had an Apgar score of 6 or less at one minute after birth. The remaining eight babies with abnormal neonatal neurological dysfunction had an Apgar score of more than 6 at one minute after birth. These eight babies had seizures during the first seven days of life but did not show any signs of altered levels of consciousness and there was no evidence of other organ ischaemia such as renal or myocardial dysfunction.

(5) Intrapartum fetal distress Of the 46 babies remaining at this stage, 35 had experienced an adverse event during labour or shortly before delivery. Twenty five mothers had an ominous cardiotocograph reading in labour, including one with a ruptured uterus and three mothers who were delivered by emergency Caesarean section following failed forceps delivery. Three babies were delivered by emergency Caesarean section in the absence of labour. Of these, two were delivered because of an ominous prelabour cardiotocograph and one was delivered at the time of fatal maternal sub-arachnoid haemorrhage. Of the seven remaining babies, three had evidence of fetal bradycardia on intermittent auscultation; one had a difficult rotational forceps delivery; one was a breech presentation diagnosed during labour at the time of delivery; in one there was a 20 minute delay in the delivery of the head of the infant at elective Caesarean section; and in the last case 
1 Has a postnatal cause for cerebral palsy been excluded? An event or illness which appears to have damaged the developing brain after the age of $\mathbf{2 8}$ days in a child previously considered to be neurologically normal.

2 Has a prenatal cause for cerebral palsy been excluded? An associated major congenital anomaly, strong family history of cerebral palsy, a chromosomal anomaly or evidence of brain malformation on neuroimaging.

3 Was there evidence of neurological dysfunction in the first week after birth?

To include babies with seizures, tone changes and altered levels of consciousness.

4 Was the baby depressed at birth?

To include babies with an Apgar score of 6 or less at one minute after birth.

Was there evidence of fetal distress or an obstetric emergency?

To include an ominous cardiotocograph, definite evidence of clinica fetal distress (particularly bradycardia) on the obstetric record, or an acute emergency such as scar rupture.

Was there evidence of suboptimal intrapartum care? Using predefined standards of care.

Children with cerebral palsy born after 37 weeks gestation
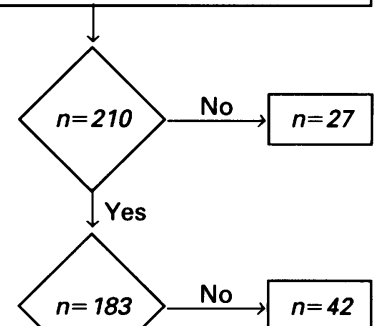

Yes

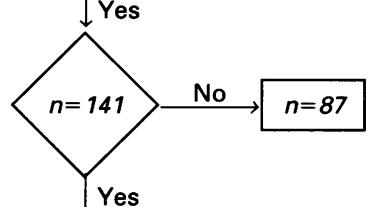

Yes

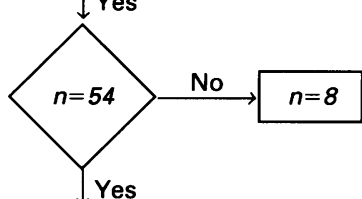

Yes

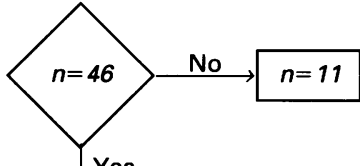

Yes

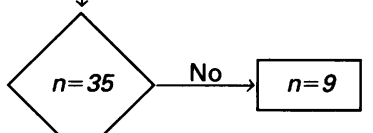

Yes

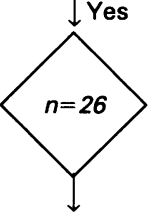

Potentially preventable cerebral palsy of intrapartum origin

Model to identify potentially preventable cerebral palsy of intrapartum origin.

attempts at delivery were made before full dilatation.

Eleven infants were excluded at this stage as no abnormality could be identified. Three mothers had continuous electronic fetal monitoring and in all cases this was normal. Two infants were delivered by elective Caesarean section, in one because there had been a previous Caesarean section and in the other because of a history of infertility in combination with unsuitability for induction of labour. The remaining six infants were not monitored but there was no evidence from intermittent auscultation that there had been any fetal heart rate abnormality during labour. In one case delivery was by Caesarean section following failure of a planned trial of forceps, but there was no evidence of fetal distress.

(6) Suboptimal intrapartum care Thirty five babies remained in the model at this stage. Using predefined criteria for care, 26 of the 35 had evidence of suboptimal intrapartum care. In the nine babies excluded at this stage there was no evidence of a failure to respond to fetal distress within times specified in the predefined criteria for care. ${ }^{26}$

\section{Discussion}

This model was developed using hypotheses about the origins of cerebral palsy derived from previous epidemiological studies. When applying the model, however, classification at each step in the model is based on the information available in the medical notes of each child.

Misclassification seemed particularly likely to occur in three areas. First, although a postnatal cause of cerebral palsy may be readily identified from medical notes, cerebral palsy of prenatal origin is less easy to diagnose. It is likely, therefore, that a number of children are misclassified at stage 2 . Most children have not had neuroimaging which might identify cerebral structural abnormalities either during the neonatal period or later childhood. We suggest that if more detailed investigations, including neuroimaging, were offered to children with cerebral palsy of uncertain origin, the size of the group of children with a 
prenatal cause of cerebral palsy would be clearer.

Second, misclassification at stages 3 and 4 can occur if seizures, which are associated with hypoxic-ischaemic encephalopathy, are not distinguished from seizures due to other conditions. If, in the neonatal period neurological signs such as levels of consciousness, seizure activity, respiratory status, feeding and signs of other organ dysfunction were systematically recorded in a standard way, it would be easier to make this distinction both at the time of the events and when notes are reviewed retrospectively.

Third, in order to classify the children as accurately as possible at stages 5 and 6 , detailed records of labour, including annotated cardiotocographs and other clinical particulars, are invaluable. These are not always available in medical and nursing records. Even in the absence of the currently accepted clinical signs of fetal distress, fetal compromise may still occur. Further research is needed on the reliability of clinical and physiological measures of fetal wellbeing.

One part of the model is not based on epidemiological evidence. The standards of care were derived from clinical consensus and many of these standards have never been subjected to rigorous testing or evaluation. This is an area of considerable debate both inside and outside the courts. We hope that the current interest in establishing standards of care based on evidence of effectiveness may help to clarify this part of the model.

As more information on the complexities of cerebral palsy becomes available, this model will need modification and refinement. In the meantime we would encourage others to test this model on other populations of children with cerebral palsy.

1 Blair E, Stanley FJ. Intrapartum asphyxia: A rare cause of cerebral palsy. F Pediatr 1988; 112: 515-20.

2 Stanley F. Perinatal risk factors in the cerebral palsies. In Stanley FJ, Alberman E, eds, The epidemiology of the cerebral palsies. Clinics in Developmental Medicine No 87 Oxford: Blackwell/Spastics International Medica Publications, 1984.

3 Nelson KB, Leviton A. How much of neonatal encephalopathy is due to birth asphyxia? Am $\mathcal{F}$ Dis Child 1991; 145 1325-31.
4 Hall DMB. Intrapartum events and cerebral palsy. $\mathrm{Br}$ f Obstet Gynaecol 1994; 101: 745-7.

5 Stanley FJ, Watson L. Trends in perinatal mortality and cerebral palsy in Western Australia, 1967 to 1985 . BMF 1992; 304: 1658-63.

6 Nelson KB, Emery ES. Birth asphyxia and the neonatal brain: what do we know and when do we know it? Clin Perinatol 1993; 20: 327-44.

7 Nelson KB. Relationship of intrapartum and delivery room events to long-term neurologic outcome. Clin Perinatol 1989; 16: 995-1007.

8 Nelson KB. Prenatal origin of hemiparetic cerebral palsy: How often and why? Pediatrics 1991; 88: 1059-62.

9 Freeman JM, Nelson KB. Intrapartum asphyxia and cerebral palsy. Pediatrics 1988; 82: 240-9.

10 Grant A, O'Brien N, Joy M-T, Henessey E, MacDonald D. Cerebral palsy among children born during the Dublin randomised trial of intrapartum monitoring. Lancet 1989; ii: $1233-6$.

11 Nelson KB, Ellenberg JH. Antecedents of cerebral palsy. Multivariate analysis of risk. $N$ Engl $\mathcal{f}$ Med 1986; 315: 81-6.

12 Nelson KB, Ellenberg JH. Antecedents of cerebral palsy: I. Univariate analysis of risks. Am $\mathcal{f}$ Dis Child 1985; 1391: 1031-8.

13 Nelson KB, Ellenberg JH. Apgar scores as predictors of chronic neurologic disability. Pediatrics 1981; 68: $36-44$.

14 Stanley FJ, Blair E. Why have we failed to reduce the frequency of cerebral palsy? Med 7 Aust 1991; 154: 623-6.

15 Colditz P, Henderson-Smart D. Electronic fetal heart rate monitoring during labour: does it prevent perinatal asphyxia and cerebral palsy? Med $f$ Aust 1990; 153: 88-90.

16 Blair E, Stanley F. Aetiological pathways to spastic cerebral palsy. Paediatr Perinat Epidemiol 1993; 7: 302-17.

17 Mutch L, Alberman E, Hagberg B, Kodama K, Perat MV. Cerebral palsy epidemiology: Where are we now and where are we going? Dev Med Child Neurol 1992; 34: 457-551.

18 Blair E, Stanley F. Intrauterine growth and cerebral palsy. 1. Association with birthweight for gestational age. $A m \mathcal{F}$ Obstet Gynecol 1990; 162: 229-37.

19 Bryce R, Stanley F, Blair E. The effects of intrapartum care on the risk of impairments in childhood. In: Chalmers I Enkin $\mathbf{M}$, Keirse $\mathbf{M}$, eds. Effective care in pregnancy and childbirth. Oxford: Oxford University Press, 1989: 1313-21.

20 Kuban KC, Leviton A. Cerebral palsy. N Engl f Med 1994; 330: 188-95.

21 Leviton A, Paneth N. White matter damage in preterm newborns - an epidemiological perspective. Early Hum Dev 1990; 24: 1-22.

22 Dale A, Stanley FJ. An epidemiological study of cerebral palsy in Western Australia, 1956-1975. II Spastic cerebral palsy and perinatal factors. Dev Med Child Neurol 1980; 22: $13-25$.

23 Paneth N, Kiely J. The frequency of cerebral palsy: A review of population studies in industrialised nations since 1950. In: Stanley FJ, Alberman E, eds. The epidemiology of the cerebral palsies. Oxford: Blackwell/Spastics International Medical Publications, 1994: w6-56.

24 Blair E, Stanley FJ. An epidemiological study of cerebral palsy in Western Australia, 1956-1975. III: Postnatal aetiology. Dev Med Child Neurol 1982; 24: 575-85.

25 Johnson A, King R. A regional register of early childhood impairments: a discussion paper. Community Med 1989; 11: $352-63$

26 Gaffney G, Sellers S, Flavell V, Squier MV, Johnson A Intrapartum care, cerebral palsy and perinatal death: $A$ case-control study. BMF 1994; 308: 743-50. 